\title{
Discrimination and characterization of different intensities of goaty flavor in goat milk by means of an electronic nose
}

\author{
C. J. Yang, W. Ding, ${ }^{1}$ L. J. Ma, and R. Jia \\ College of Food Science and Engineering, Northwest A\&F University, Yangling 712100, China
}

\begin{abstract}
An electronic nose based on metal oxide sensors was used to measure goaty flavor in goat milk samples. To study the relationships between electronic nose data, sensory data, and levels of free fatty acids (FFA), multivariate partial least square regression (PLS) was carried out. The electronic nose system evaluation correlated well with sensory evaluation. The coefficients of determination $\left(\mathrm{R}^{2}\right)$ of the PLS models reached $90.0 \%$. The electronic nose, combined with principal component analysis and linear discriminant analysis, can discern among goat milk samples with different goaty flavor intensities. In addition, Fisher discriminant analysis and back-propagation neural network were carried out to evaluate goaty flavor intensity, and the prediction accuracies were 98.2 and $100.0 \%$, respectively. The electronic nose is a potentially useful tool to evaluate goaty flavor intensity in goat milk samples.
\end{abstract}

Key words: goaty flavor, goat milk, electronic nose, sensory analysis, multivariate data analysis

\section{INTRODUCTION}

Goat milk is a valuable food product and an excellent raw material from which products of highly nutritive value are made. There is increasing research interest in goat milk due to inherent species-specific biochemical properties that contribute to its nutritional quality (Raynal-Ljutovac et al., 2008; Strzałkowska et al., 2012; Jirillo and Magrone, 2014). However, the flavor of goat milk is different from that of cow milk, and the goaty flavor may prove unacceptable to some consumers, which limits market opportunities for goat milk (Haenlein, 2004). The development of goaty flavor is due to straight-chain FFA, mainly C6:0 to C9:0 (Skjevdal, 1979; Chilliard et al., 2003; Eknæs et al., 2006), and some branched-chain C9:0 and C10:0 FFA (Kim Ha and Lindsay, 1993). Goaty flavor is influenced by factors such as goat breed, feeding model, and in-

Received June 23, 2014.

Accepted September 29, 2014.

${ }^{1}$ Corresponding author: dingv1055@163.com dustrial process (Skjevdal, 1979; Morgan and Gaborit, 2001; Chilliard et al., 2003).

Flavor is a major attribute that influences the selection and consumption of foods. The analysis of characteristic food flavors has commonly been carried out by human assessment and instrumental analysis. For sensory analysis, taste and aroma are assessed by trained sensory panels. The main issues of this method are measurement standardization, stability, and reproducibility. In addition, the high cost of training people and the use of sensory panels limit the applications of this technique (He et al., 2009; Santos et al., 2010; Russo et al., 2013). Instrumental techniques such as GC, GC-MS, and HPLC have high operating costs and are time consuming (Cozzolino et al., 2005; Qin et al., 2013; Tian et al., 2013). Furthermore, instrumental methods usually separate the aroma into its individual components. This situation in the analysis of food flavors indicates the need for a more objective approach.

One approach for sensory analysis is the use of an electronic nose. The device consists of an array of chemical gas sensors with a broad and partly overlapping selectivity for the measurement of volatile compounds within the headspace over a sample combined with computerized multivariate statistical data processing tools (Gardner and Bartlett, 1994). In principle, both the electronic nose and the human nose operate by simultaneously sensing a large number of components, giving rise to a specific response pattern (Haugen and Kvaal, 1998). The electronic nose assesses the mixture of volatiles released from a sample and has the advantage of being nondestructive and portable, with low cost and good reliability (Echeverría et al., 2004; Zhang et al., 2007).

The electronic nose has been used successfully to evaluate dairy products for aging of milk, (Capone et al., 2000b, 2001), shelf-life prediction (Labreche et al., 2005), classification of bacteria cultures in milk (Magan et al., 2001; Ali et al., 2003), classification by geographical origin of a dairy product (Pillonel et al., 2003), and classification of cheese (Jou and Harper, 1998; Capone et al., 2000a). Meanwhile, the electronic nose has been applied successfully to evaluate odors in environmental contamination cases (Persaud et al., 1996; Stuetz et al., 
1999; Sohn et al., 2003; Nake et al., 2005) and to quantify off-flavors in meat foods (Annor-Frempong et al., 1998; Grigioni et al., 2000; Vestergaard et al., 2006; Tikk et al., 2008; Song et al., 2013). Nevertheless, a few studies have discriminated the goaty flavor intensity of goat milk by electronic nose coupled with multivariate data analysis. Therefore, the aim of this work was to investigate the potential of the electronic nose as a useful tool to discriminate the intensity of goaty flavor in goat milk.

\section{MATERIALS AND METHODS}

\section{Sample Preparation}

Raw goat milk was obtained from the Xinong Saanen dairy goat seed farm in Yangling (Shaanxi Province, China). We have found that the addition of FFA to skim milk does not contribute to typical goaty flavor. Thus, samples with different goaty flavor intensities were prepared by adding different percentages of goat milk lipids to skim goat milk. The preparation process was as follows: (1) goat milk lipids were obtained from raw goat milk by centrifugation at 2,795 $\times g$ at room temperature for $10 \mathrm{~min}$; (2) the lipids were added back to the skim milk at different concentrations to obtain goat milk samples with different goaty flavor intensities (6 groups of goat milk samples with varying goaty flavor intensities were prepared); and (3) the reconstituted milks were homogenized and sterilized $\left(65^{\circ} \mathrm{C}, 30 \mathrm{~min}\right)$. The samples were stored at $-40^{\circ} \mathrm{C}$ in sealed sterile glass bottles for further analysis.

Bronopol was added (final concentration: 400 $\mathrm{mg} / \mathrm{L}$ ) before analysis to prevent microbial growth (Eriksson et al., 2005). All samples were assessed by sensory panel, FFA analysis, and the electronic nose to generate data.

\section{Electronic Nose Analysis}

The electronic nose device (PEN 3 Portable Electronic Nose, Airsense Analytics GmbH, Schwerin, Germany) contains a detector unit with an array of 10 different metal oxide sensors. The main applications of the 10 sensors and a schematic diagram of the electronic nose are shown in Table 1 and Figure 1 (Airsense Analytics GmbH, 2008).

Six groups of samples (which were created by the method described in sample preparation section) were assessed with different goaty flavor intensities, each group was divided into $40(10.0 \mathrm{~mL})$ samples, and each sample was evaluated in duplicate. To perform the electronic nose assay, $10.0 \mathrm{~mL}$ of the sample was put into a $50-\mathrm{mL}$ glass vial with a Teflon/silicon septum in the screw cap. The sample was equilibrated for $30 \mathrm{~min}$ at $25^{\circ} \mathrm{C}$ to allow for the development of headspace before electronic analysis. Thereafter, one Luer-lock needle connected to a Teflon tubing $(3 \mathrm{~mm})$ was used to perforate the seal of the vial and to absorb the air accumulated inside it with a flow rate of 400 $\mathrm{mL} / \mathrm{min}$ during the measurement. The sensor response was defined as the ratio of conductance $\mathrm{G}_{0} / \mathrm{G}$ or $\mathrm{G} / \mathrm{G}_{0}$ (where $\mathrm{G}_{0}$ and $\mathrm{G}=$ conductance of the sensor before and after exposure to the gas samples, respectively). Data were recorded every second by a computer, and the experiment lasted for $60 \mathrm{~s}$ (long enough for the sensors to stabilize). Recovery time for the sensors was $240 \mathrm{~s}$ (flushing with reference air). The set of signals of the sensors during measurement of a sample formed patterns, which were analyzed in random order. The response values were stable and reproducible in repeated measurements. The electronic nose was used at $25^{\circ} \mathrm{C} \pm$ 2 during all experiments.

\section{Sensory Evaluation}

The sensory analysis was carried out to detect the intensity of goaty flavor in the samples using the quantitative response scales method (ISO 4121; ISO, 2003). The trained sensory panel consisted of 12 university students (6 men and 6 women) with a mean age of 25 yr and previous experience in sensory evaluation. The panelists were trained on flavor profiles, the sniffing technique, the use of scales, and the intensity rating procedure, in accordance with international standards (ISO 8586; ISO, 2012). The sensory training was carried out before sensory testing. The whole training took approximately $42 \mathrm{~h}$ over $4 \mathrm{wk}$.

For the evaluation, $10.0 \mathrm{~mL}$ of sample was weighed into a $50-\mathrm{mL}$ screw cap glass bottle. Beforehand, the bottles were kept for $30 \mathrm{~min}$ in a $25^{\circ} \mathrm{C}$ regulated oven to help the flavor develop in the headspace. This preparation facilitated flavor perception by the panelists. Milk samples were coded with randomly chosen 3-digit numbers and presented in random order. Panelists were instructed to remove the lid of the bottle, take 3 short sniffs and taste, and then rate the overall intensity of the samples according to a predetermined attribute scale, ranging from 0 (none) to 10 (very strong). A 4-class evaluation scheme was then used. The first class (none; no goaty flavor) scored 0 ; the second class (low; slight goaty flavor) scored $\geq 1$ to $<4$; the third class (mild; clearly goaty flavor) scored $\geq 4$ to $<7$; and the fourth class (strong; strong goaty flavor) scored $\geq 7$. Overall, the goat milk samples were scored by the trained panel and discriminated into the defined groups as none, low, mild, and strong. Deionized water was provided to the panelists to clear their palates. Skim cow milk and goat milk fat were used as reference samples during training 


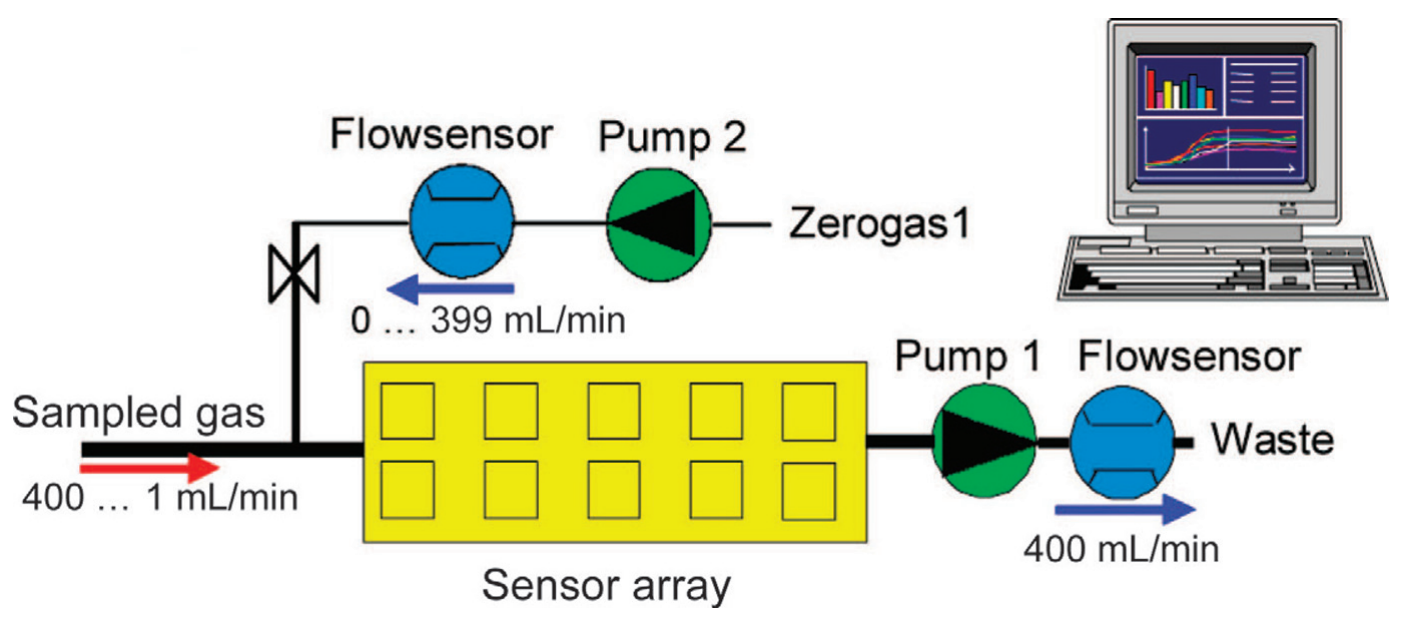

Figure 1. Schematic diagram of electronic nose measurement (PEN 3 Portable Electronic Nose, Airsense Analytics GmbH, Schwerin, Germany) during experiments. Color version available online.

and sensory testing. Three replicates were measured using separate repeat samples.

\section{FFA Goaty Flavor Analysis}

The FFA C6:0, C8:0, and C10:0 were separated from the fat by multilevel solvent extraction, converted to their methyl esters, and analyzed by GC as described by Spaepen et al. (1978) with some modifications. Samples were run in duplicate. In brief, the milk samples (10.0 $\mathrm{mL})$ were mixed with $1 \mathrm{~mL}$ of $\mathrm{H}_{2} \mathrm{SO}_{4}(2.5 \mathrm{moL} / \mathrm{L}), 2 \mathrm{~g}$ of $\mathrm{NaCl}$, and $500 \mu \mathrm{L}$ of a standard solution of nonanoic acid (200.00 mg/L in HPLC-grade hexane). Extraction was carried out with $25 \mathrm{~mL}$ of chloroform/methanol $(2: 1, \mathrm{vol} / \mathrm{vol})$ in a $50-\mathrm{mL}$ screw-capped centrifuge tube. The lower organic solvent layer was transferred to the second tube and the extraction procedure was repeated twice. The pooled extract was extracted 3 times with $5 \mathrm{~mL}$ of $\mathrm{Na}_{2} \mathrm{CO}_{3}(50 \mathrm{~g} / \mathrm{L})$ and the aqueous phase was collected. After the aqueous phase had been acidified to $\mathrm{pH} 2$ with $\mathrm{HCl}(5 \mathrm{~mol} / \mathrm{L})$, the $\mathrm{FFA}$ were finally extracted 3 times with $5 \mathrm{~mL}$ of chloroform/methanol $(2: 1, \mathrm{vol} / \mathrm{vol})$. The combined solution was dried with anhydrous $\mathrm{Na}_{2} \mathrm{SO}_{4}$ and brought to near dryness by passing a stream of nitrogen across. Thereafter, the FFA were methylated with $1 \mathrm{~mL}$ of $\mathrm{BF}_{3} / \mathrm{CH}_{3} \mathrm{OH}(14 \%$, wt/wt) for about $20 \mathrm{~min}$ in a water bath at $80^{\circ} \mathrm{C}$. After cooling the methylated FFA to room temperature, 1 $\mathrm{mL}$ of hexane and $1 \mathrm{~mL}$ of saturated aqueous $\mathrm{NaCl}$ were added, mixed thoroughly, and left overnight at $-40^{\circ} \mathrm{C}$ for phase separation. The top hexane layer $(2$ $\mu \mathrm{L})$ containing methylated fatty acids were analyzed for FA composition using a GC (Shimadzu GC-2014C, Kyoto, Japan) with a DB-17 column (30 m, $0.25 \mathrm{~mm}$ i.d., Agilent, Santa Clara, CA) for separation of fatty acids. Temperatures of the inlet and flame-ionization detector were $260^{\circ} \mathrm{C}$ and $280^{\circ} \mathrm{C}$, respectively. The oven temperature was kept at $120^{\circ} \mathrm{C}$ for $5 \mathrm{~min}$ and then programmed to reach $240^{\circ} \mathrm{C}$ at a rate of $4^{\circ} \mathrm{C} / \mathrm{min}$, with a final isotherm of $15 \mathrm{~min}$. The pressures of the flame-

Table 1. Sensors used and their main applications in the electronic nose device (PEN 3 Portable Electronic Nose, Airsense Analytics GmbH, Schwerin, Germany)

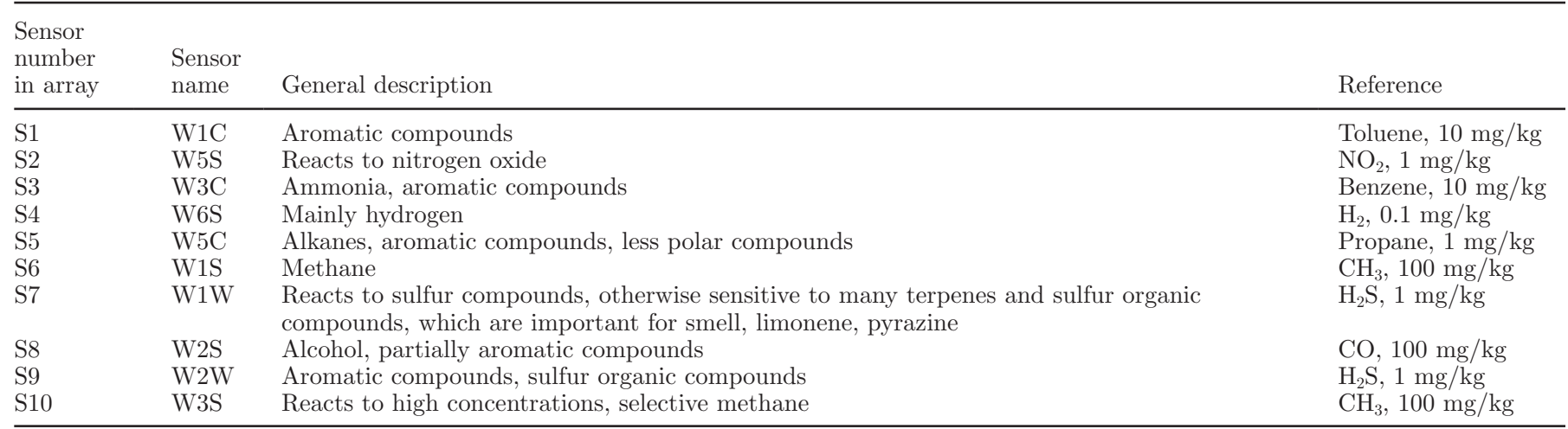


ionization detector air, hydrogen gas, and carrier gas (high-purity nitrogen, $\geq 99.999 \%$ ) were 50,75 , and 100 $\mathrm{kPa}$, respectively. The injection port was operated in split mode (1:5). The FA were identified by comparing the peak retention times with standards (Aladdin, Shanghai, China).

\section{Data Analysis}

The data obtained from the sensor array of the electronic nose were analyzed by principal component analysis (PCA), linear discriminant analysis (LDA), back-propagation neural network (BP-NN), and partial least squares regression (PLS). All data analysis was performed using Matlab (version 2010a; Math Works Inc., Natick, MA) and SPSS version 20.0 (SPSS/ IBM, Armonk, NY).

\section{RESULTS AND DISCUSSION}

\section{Characteristics of Goat Milk Samples}

The goat milk samples were characterized by their titratable acidity, $\mathrm{pH}$, fat content, and nonfat solids content. The characteristics of goat milk samples used in this study are shown in Table 2 . To provide a range of low to high goaty flavor intensities, a concentration series of fat was chosen to add to the skim milk. Table 2 also lists the contents of the $3 \mathrm{FFA}$ in the samples.

\section{Sensory Evaluation}

Flavor is defined as the combined effect of olfactory (aroma) and gustatory (taste) sensations (Wilson and Baietto, 2009). Goaty aroma is the result of the sensation elicited by several goaty flavor molecules that reach the olfactory receptor by air passing through the nose or the mouth and nasopharynx into the nose. The results of the sensory test of the goat milk samples are summarized in Table 3. Clear differences between the different samples were evident in relation to goaty flavor attributes. Data also showed that the degree of goaty flavor increased with increasing concentrations of the $3 \mathrm{FFA}$ in the samples. Goaty flavor was higher in taste intensity than in smell intensity, and the findings were consistent with previously reported research (Grazier et al., 1991). The presence of relatively high levels of medium-chain fatty acids (C6:0 to C10:0) in goat milk fat could be responsible for its inferior flavor (Skjevdal, 1979). Hexanoic acid (C6:0) is described as having pungent, goaty, sweaty, and blue cheese flavor notes; octanoic acid (C8:0) has wax, soap, goaty, musty, rancid, and fruity notes; and decanoic acid (C10:0) is described as soapy, bitter, goaty and rancid (Woo and Lindsay, 1983; Salles et al., 2002; Collins et al., 2003). The reported flavor thresholds in citrate-phosphate buffer at $\mathrm{pH} 6.0$ of $\mathrm{C6}: 0, \mathrm{C} 8: 0$, and $\mathrm{C} 10: 0$ are 27.1, 11.3 , and $14.8 \mathrm{ppm}$, respectively (Brennand and Lindsay, 1982). The buffering action at the normal $\mathrm{pH}$ of milk tends to sequester acids and raise thresholds above those found in water (Patton, 1964). Previously reported flavor thresholds for C6:0, C8:0, and C10:0 were 14, 23, and $28 \mathrm{ppm}$ in milk (Siek et al., 1969). The 3 FFA can contribute to goaty flavor when the concentrations exceed the threshold value of each. Moreover, mixtures of compounds have been shown to complicate interpretation because the threshold value for an FFA in a mixture is lowered by the presence of high concentrations of other FFA due to synergistic interactions (Woo and Lindsay, 1983). In our study, concentrations of C6:0 in all samples ranged from 7.98 to $15.12 \mathrm{mg} / \mathrm{L}$, concentrations of C8:0 ranged from 5.41 to $23.03 \mathrm{mg} / \mathrm{L}$, and concentrations of $\mathrm{C} 10: 0$ ranged from 9.60 to 69.95 $\mathrm{mg} / \mathrm{L}$ (Table 2). Therefore, the FFA were expected to influence goaty flavor when they were present at supra-threshold concentrations in milk, and they might also have expressed goaty flavor by synergistic effects when they were present at low concentrations in milk. It should be noted that thresholds depend greatly on the expertise of panelists and character of media (such as $\mathrm{pH}$ ), thus the thresholds of FFA differ among studies (Brennand et al., 1989). The goaty flavor probably de-

Table 2. Chemical and physical indices (mean \pm SD) of goat milk samples

\begin{tabular}{|c|c|c|c|c|c|c|c|}
\hline $\begin{array}{l}\text { Sample } \\
\text { type }\end{array}$ & $\mathrm{pH}$ & $\begin{array}{l}\text { Titratable } \\
\left.\text { acidity ( }{ }^{\circ} \mathrm{T}\right)\end{array}$ & $\begin{array}{c}\text { Fat } \\
(\mathrm{g} / 100 \mathrm{~g})\end{array}$ & $\begin{array}{c}\text { Nonfat } \\
\text { solids }(\mathrm{g} / 100 \mathrm{~g})\end{array}$ & $\begin{array}{c}\mathrm{C} 6: 0 \\
(\mathrm{mg} / \mathrm{L})\end{array}$ & $\begin{array}{c}\mathrm{C} 8: 0 \\
(\mathrm{mg} / \mathrm{L})\end{array}$ & $\begin{array}{l}\text { C10:0 } \\
(\mathrm{mg} / \mathrm{L})\end{array}$ \\
\hline Group 1 & $6.53 \pm 0.02$ & $12.0 \pm 0.4$ & $2.58 \pm 0.04$ & $9.13 \pm 0.06$ & 7.98 & 5.41 & 9.60 \\
\hline Group 2 & $6.20 \pm 0.01$ & $16.4 \pm 0.4$ & $0.37 \pm 0.01$ & $8.06 \pm 0.06$ & 8.15 & 8.80 & 12.46 \\
\hline Group 3 & $6.17 \pm 0.01$ & $18.0 \pm 0.3$ & $3.97 \pm 0.03$ & $7.82 \pm 0.03$ & 11.8 & 15.02 & 38.32 \\
\hline Group 4 & $6.08 \pm 0.02$ & $17.5 \pm 0.3$ & $6.07 \pm 0.06$ & $7.62 \pm 0.03$ & 12.77 & 18.93 & 47.73 \\
\hline Group 5 & $6.01 \pm 0.01$ & $18.0 \pm 0.3$ & $8.96 \pm 0.04$ & $7.40 \pm 0.01$ & 13.66 & 19.43 & 57.69 \\
\hline Group 6 & $5.81 \pm 0.01$ & $18.7 \pm 0.3$ & $11.34 \pm 0.02$ & $7.20 \pm 0.01$ & 15.12 & 23.03 & 69.95 \\
\hline
\end{tabular}

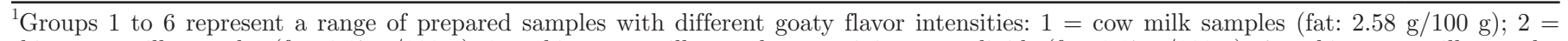

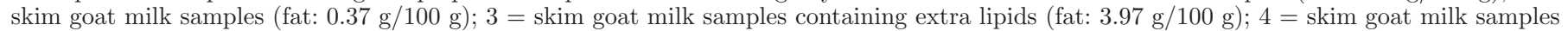

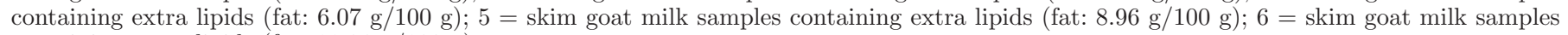
containing extra lipids (fat: $11.36 \mathrm{~g} / 100 \mathrm{~g}$ ). 
pended on a concentration balance of the FFA reported herein. Synergistic interactions exhibited by mixtures probably had some effect in giving goat milk its goaty flavor. Furthermore, some branched-chain FFA have lower flavor thresholds than their straight-chain analogs and also exhibit goaty flavor (Salles et al., 2002), but the low concentrations of these acids in milk precluded their direct measurement by the method used in this study. Therefore, additional methods for quantifying branched-chain acids should be used to analyze the goaty flavor characterization. Relevant work in this area will be performed by our laboratory in the future.

\section{Sensor Array Response to Goat Milk Samples}

The analyses by electronic nose were carried out on the same samples used for GC and sensory evaluation. Figure 2 shows the evolution of the typical response value generated by the sensor array (10 sensors) exposed to the headspace of one of the samples. For one sample, each curve presented a different transient sensor response. The sensor response was given as $G / G_{0}$, where $G_{0}$ and $G$ express the resistance of a sensor in zero gas and in sample gas, respectively. After an initial period of low and stable conductivity, the conductivities of sensors (S)4, S6, S7, and S8 increased sharply and then stabilized after $40 \mathrm{~s}$. For the rest of the sensors, especially S1, S3, and S5, little change in resistance occurred over the detection time.

Generally, the sensor signal used in electronic nose analysis should be stabilized. Therefore, the mean stable signal of each sensor, at a response time of 55 to $59 \mathrm{~s}$, was used in this study. Outliers were abnormal measure-

Table 3. Means for sensory evaluation of different grades of goat milk samples

\begin{tabular}{lcccl}
\hline & \multicolumn{3}{c}{ Average intensity score $^{2}$} & \\
\cline { 2 - 3 } Sample $^{1}$ & Smell & Taste & Total & Classification \\
\hline Group 1 & 0 & 0 & 0 & None \\
Group 2 & 2 & 1 & 3 & Low \\
Group 3 & 3 & 2 & 5 & Low \\
Group 4 & 6 & 3 & 9 & Mild \\
Group 5 & 8 & 6 & 14 & Strong \\
Group 6 & 9 & 8 & 17 & Strong \\
\hline
\end{tabular}

${ }^{1}$ Groups 1 to 6 represent a range of prepared samples with different goaty flavor intensities: 1 = cow milk samples (fat: $2.58 \mathrm{~g} / 100 \mathrm{~g}$ ) $; 2=$ skim goat milk samples (fat: $0.37 \mathrm{~g} / 100 \mathrm{~g}$ ); $3=$ skim goat milk samples containing extra lipids (fat: $3.97 \mathrm{~g} / 100 \mathrm{~g}$ ); $4=$ skim goat milk samples containing extra lipids (fat: $6.07 \mathrm{~g} / 100 \mathrm{~g}$ ); 5 = skim goat milk samples containing extra lipids (fat: $8.96 \mathrm{~g} / 100 \mathrm{~g}$ ); $6=$ skim goat milk samples containing extra lipids (fat: $11.36 \mathrm{~g} / 100 \mathrm{~g}$ ).

${ }^{2}$ Values were rounded to whole numbers.

${ }^{3}$ Goaty flavor intensities: none $=$ sample score is 0 ; low $=$ sample score is $\geq 1$ and $<4$; mild $=$ sample score is $\geq 4$ and $<7$; strong $=$ sample score is $>7$.

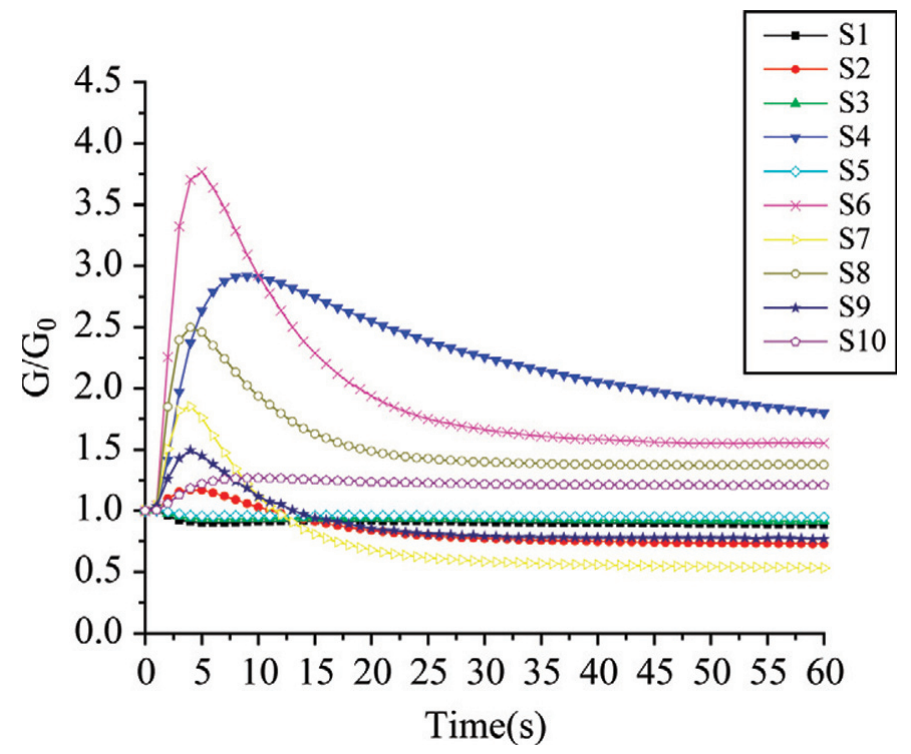

Figure 2. Typical pattern of electronic nose sensor response for a sample of goat milk samples. $G / G_{0}$ represents the gas response, where $\mathrm{G}_{0}$ and $\mathrm{G}$ express the resistance of a sensor in zero air and in sample gas, respectively. S1 to 10 represent the sensor number in the array: $\mathrm{S} 1=$ sensor W1C; $\mathrm{S} 2=$ sensor W5S; $\mathrm{S} 3=$ sensor W3C; $44=$ sensor $\mathrm{W} 6 \mathrm{~S} ; \mathrm{S} 5=$ sensor $\mathrm{W} 5 \mathrm{C} ; \mathrm{S} 6=$ sensor $\mathrm{W} 1 \mathrm{~S} ; \mathrm{S} 7=$ sensor $\mathrm{W} 1 \mathrm{~W} ; \mathrm{S} 8$ $=$ sensor $\mathrm{W} 2 \mathrm{~S} ; \mathrm{S} 9=$ sensor $\mathrm{W} 2 \mathrm{~W} ; \mathrm{S} 10=$ sensor $\mathrm{W} 3 \mathrm{~S}$. Color version available online.

ments that deviated from the bulk of samples. In this paper, outliers of the electronic nose data were excluded by the minimum covariance determinant estimator (Verboven and Hubert, 2005) before further analysis. Figure 3 shows the mean responses of the electronic nose sensors of all samples analyzed. The profile of the radial plot indicates that the sensors gave similar signals for all samples. Although sensor signals presented variable responses for the samples without being able to assign a particular trend, the response strength of some sensors (such as S4, S6, S7, S8, and S9) was different. As shown in Table 1, the S4 sensor detects mainly hydrogen; the S6 sensor detects methane; the S7 sensor detects sulfur compounds, terpenes, and sulfur organic compounds; and the S8 and S9 sensors are selective toward aromatic compounds. These sensors generated essentially similar information, so we can infer that the ways of these sensors responded to the volatiles was very similar. However, reaction mechanisms were not proposed because of a lack of detailed information on the features of these sensors as well as an insufficient understanding of the physicochemical changes in the sensors using traditional chemistry (Smyth and Cozzolino, 2013). More research is needed to interpret the results; however, we found that 5 sensors (S4, S6, S7, S8, and S9) were more important than the others on the current pattern file in evaluating intensities of goaty flavor in goat milk. 


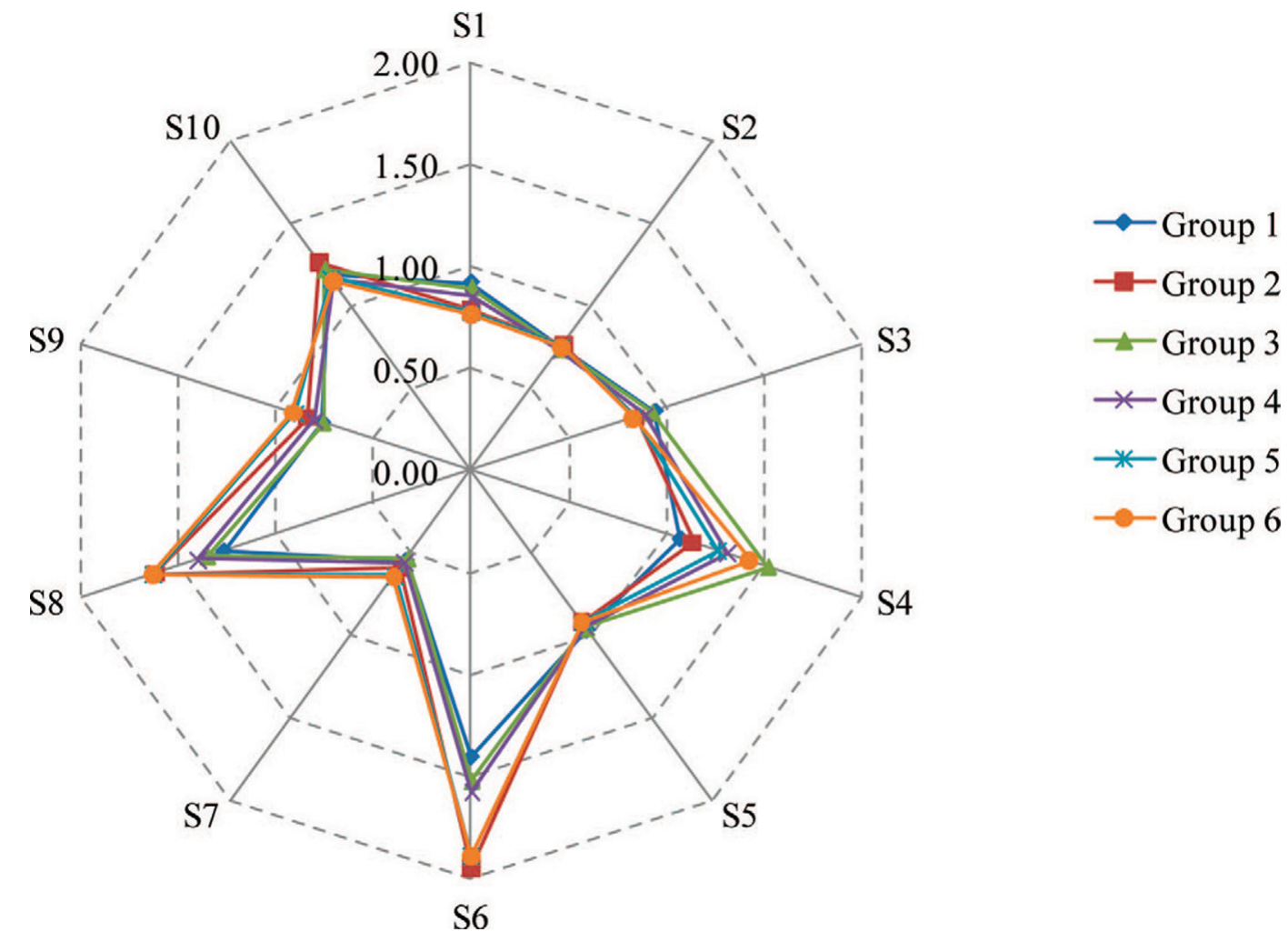

Figure 3. Polar plots of the responses of the array of sensors toward the goat milk samples. Groups 1 to 6 represent a range of prepared samples with different goaty flavor intensities: $1=$ cow milk samples (fat: $2.58 \mathrm{~g} / 100 \mathrm{~g}$ ); $2=$ skim goat milk samples (fat: $0.37 \mathrm{~g} / 100 \mathrm{~g}$ ); $3=$ skim goat milk samples containing extra lipids (fat: $3.97 \mathrm{~g} / 100 \mathrm{~g}$ ); $4=$ skim goat milk samples containing extra lipids (fat: $6.07 \mathrm{~g} / 100 \mathrm{~g}$ ); 5 = skim goat milk samples containing extra lipids (fat: $8.96 \mathrm{~g} / 100 \mathrm{~g}$ ); 6 = skim goat milk samples containing extra lipids (fat: $11.36 \mathrm{~g} / 100 \mathrm{~g}$ ); numbers S1 to 10 represent the sensor numbers in the array: $1=$ sensor W1C; $2=$ sensor W5S; $3=$ sensor W3C; $4=$ sensor W6S; $5=$ sensor W5C; $6=$ sensor W1S; $7=$ sensor W1W; $8=$ sensor W2S; $9=$ sensor $\mathrm{W} 2 \mathrm{~W} ; 10=$ sensor W3S; the axis displays the response $\left(\mathrm{G} / \mathrm{G}_{0}\right)$ values (which range from 0.00 to 2.00 ). Color version available online.

For better visualization of data in a reduced dimension, PCA was performed to identify patterns of correlation with individual composition variables involved in the discrimination among different milk samples (Figure 4). Principal component analysis can compress data based on their similarities and differences by reducing the number of dimensions without much loss of information, and by defining the number of principal components (PC; Rodriguez-Campos et al., 2011). The score plot revealed that $\mathrm{PC} 1$ and $\mathrm{PC} 2$ represented 68.6 and $18.3 \%$ of the total variance, respectively. The accumulated contribution rate of the first $2 \mathrm{PC}$ was $86.9 \%$, which appeared to provide enough information of the samples (He et al., 2006). Although several groups of samples partially overlapped each other and convergence of each group was inferior, data sets for all samples appeared separated for each group.

To achieve clear separation between different samples, the same data set was analyzed by LDA, a supervised pattern recognition method that maximizes the ratio of between-class variance and minimizes the ratio of within-class variance. As shown in Figure 5, the first 2 linear discriminant (LD) factors (explaining $88.5 \%$ of the total variance of the data set, $63.8 \%$ by LD1 and $24.7 \%$ by LD2) gave the most information of optimized data set and were high enough to represent all the variables. Clusters were clearly separated, with the exception of group 5 and group 6 , which appeared slightly mixed. The 6 groups were more identifiable by LDA than by PCA.

Despite the sensor instability in some cases, the diverse results of different groups in PCA and LDA analysis confirmed the ability of the electronic nose to differentiate intensities of goaty flavor in goat milk.

\section{Relationship Among Electronic Nose System, GC Data, and Sensory Attributes}

The correlations between electronic nose sensor responses, FFA profiles, and sensory attributes were analyzed by PLS. The regression models were projected using the full cross-validation method. 


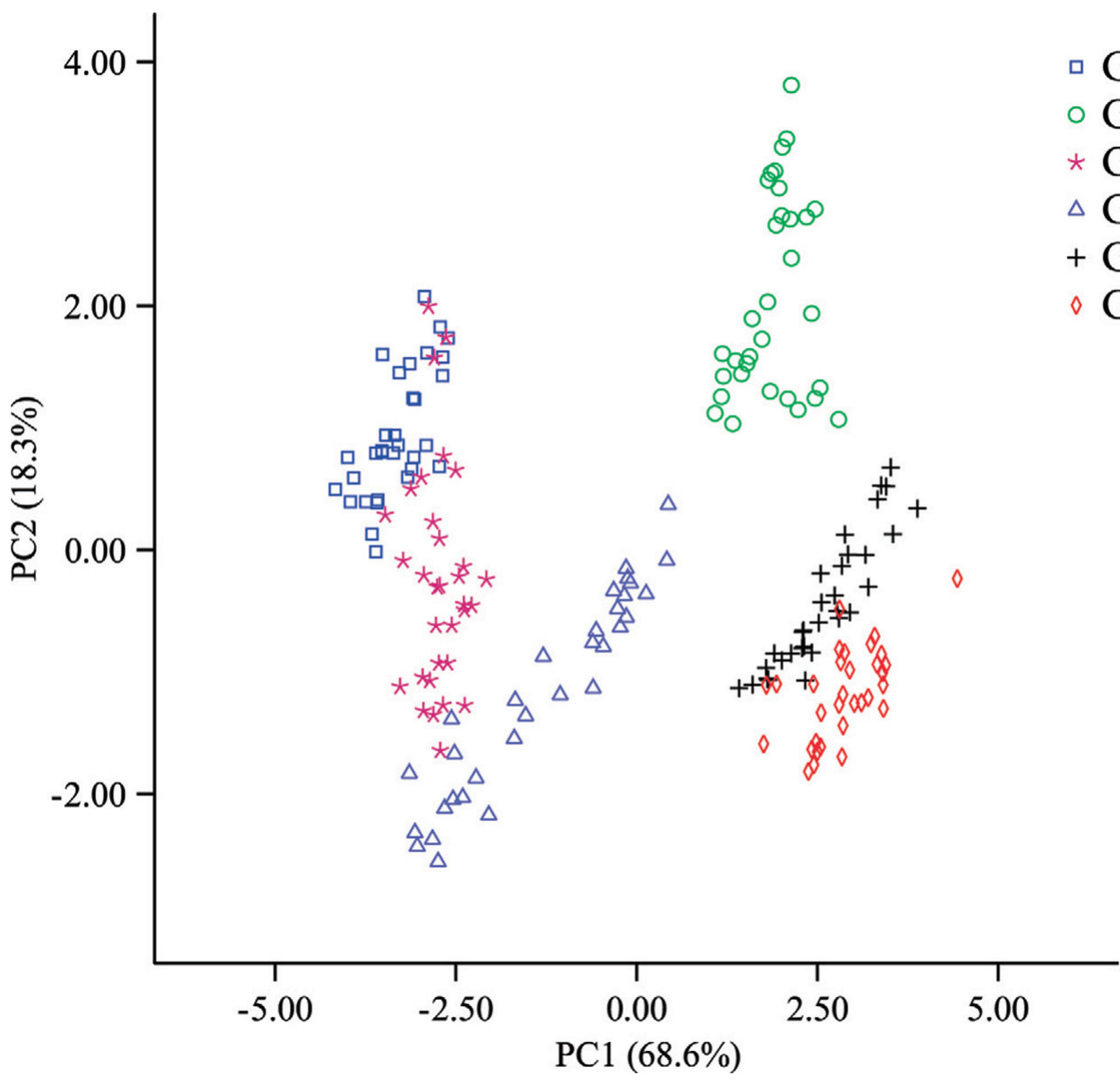

Figure 4. Principal components analysis score plot of goat milk samples with principal components (PC) 1 and PC2. Groups 1 to 6 represent a range of prepared samples with different goaty flavor intensities: $1=$ cow milk samples (fat: $2.58 \mathrm{~g} / 100 \mathrm{~g}$ ); $2=$ skim goat milk samples (fat: $0.37 \mathrm{~g} / 100 \mathrm{~g}$ ); 3 = skim goat milk samples containing extra lipids (fat: $3.97 \mathrm{~g} / 100 \mathrm{~g}$ ); 4 = skim goat milk samples containing extra lipids (fat: $6.07 \mathrm{~g} / 100 \mathrm{~g}$ ); 5 = skim goat milk samples containing extra lipids (fat: $8.96 \mathrm{~g} / 100 \mathrm{~g}$ ); 6 = skim goat milk samples containing extra lipids (fat: $11.36 \mathrm{~g} / 100 \mathrm{~g})$. Color version available online.

Relationship Between Electronic Nose Data and GC Data. To investigate the relationships between electronic nose data and GC data, a PLS analysis was carried out. The X-matrix was designated as electronic nose data and the Y-matrix was designated as GC data. The root mean standard error of crossvalidation (RMSECV) and the coefficient of determination $\left(\mathrm{R}^{2}\right)$ between measured and predicted values were computed to evaluate the predictive ability of the models. Larger $\mathrm{R}^{2}$ and lower RMSECV indicate a better calibration model. Figure 6 shows the prediction ability for content of C6:0, C8:0, and C10:0 by electronic nose. The ordinate and abscissa represent the predicted and measured fitted values of the appropriate parameters, respectively. The correlation between the measured and predicted values for each characteristic showed moderate to excellent prediction performance. Moreover, the $\mathrm{R}^{2}$ of model of C6:0, C8:0, and C10:0 reached 0.96, 0.94, and 0.96 , respectively, with RMSECV of $0.57,1.48$, and $4.48 \mathrm{mg} / \mathrm{L}$ (Table 4). The results illustrated good linear correlation between the electronic nose data and the content of the $3 \mathrm{FFA}$.

The electronic nose uses arrays of sensors that can be used to monitor volatile compounds. The electronic nose had been successful for identifying the content of volatile components (Persaud et al., 1996; Di Natale et al., 2003; Fernandes and Gomes; 2008; Arroyo et al., 2009). Further experiments in our laboratory showed that the electronic nose, combined with PCA and LDA, was able to identify differences in contents of C6:0, C8:0, and C10:0 (data not shown). However, the sensors did not achieve the sensitivity and selectivity of traditional instrumental techniques, such as GC analysis (Smyth and Cozzolino, 2013). Electronic noses are not specifically designed to detect particular volatile compounds; rather, they are used to recognize the combination of individual chemical compound in the generation of odors. Therefore, electronic nose 


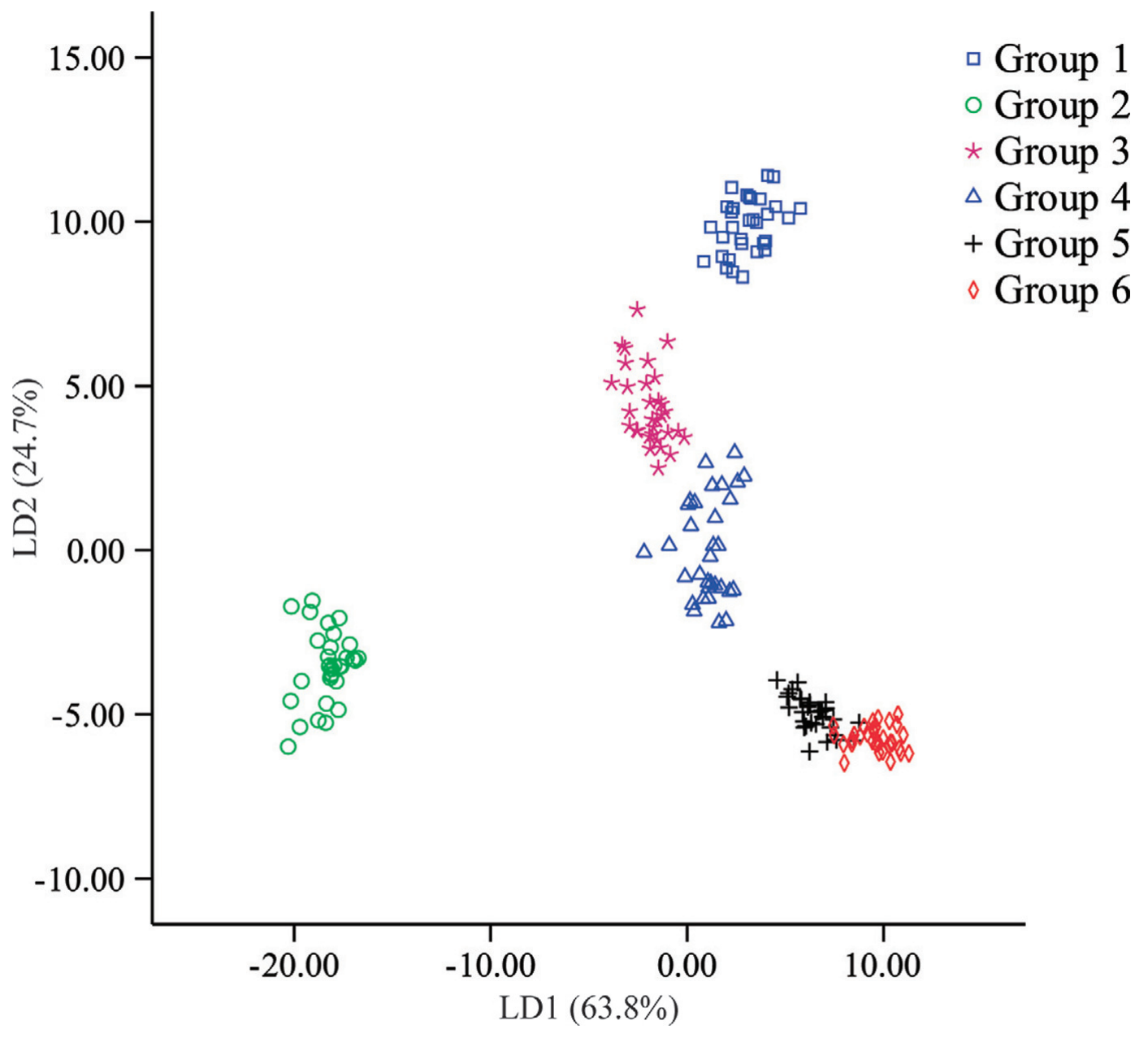

Figure 5. Linear discriminant (LD) analysis score plot of goat milk samples with LD1 and LD2. Groups 1 to 6 represent a range of prepared samples with different goaty flavor intensities: $1=\mathrm{cow}$ milk samples (fat: $2.58 \mathrm{~g} / 100 \mathrm{~g}$ ); 2 = skim goat milk samples (fat: $0.37 \mathrm{~g} / 100 \mathrm{~g}$ ); $3=$ skim goat milk samples containing extra lipids (fat: $3.97 \mathrm{~g} / 100 \mathrm{~g}$ ); $4=$ skim goat milk samples containing extra lipids (fat: $6.07 \mathrm{~g} / 100 \mathrm{~g}$ ); $5=$ skim goat milk samples containing extra lipids (fat: $8.96 \mathrm{~g} / 100 \mathrm{~g}$ ); 6 = skim goat milk samples containing extra lipids (fat: $11.36 \mathrm{~g} / 100 \mathrm{~g}$ ). Color version available online.

technology is not yet able to fully replace traditional instrumental analytical methods.

Relationships Between Electronic Nose Data and Sensory Scores. To examine the relationships between the whole electronic nose data and sensory scores, 2 data sets were analyzed by PLS. Independent variables (the electronic nose sensor responses) were used to predict a set of sensory scores (dependent variables). The prediction results by PLS are shown in Figure 7. The results show good correlation between the responses of the electronic nose sensors and the sensory scores, and the predictability was reasonably $\operatorname{good}\left(\mathrm{R}^{2}=0.97, \mathrm{RMSECV}=1.06\right)$. Thus, test sample results with the electronic nose could be successfully projected onto the prediction of sensory scores.

Electronic noses are engineered to mimic the mammalian olfactory system (Wilson and Baietto, 2009).
Previous research work has found good correlations between sensory evaluations and nose signal responses (Miettinen et al., 2002; Ohmori et al., 2005; Tamaki et al., 2008; Tikk et al., 2008). Today, however, a sensory panel can provide information about sensory properties that is far richer than that provided by instrumental devices alone, and the electronic nose should not completely replace current sensory assessment process using human subjects. We suggest that the electronic nose can be a useful auxiliary tool for goaty flavor assessment.

Relationships Between Sensory Scores and GC Data. The relationships between sensor scores and GC data were established by PLS with GC data (X-matrix) and sensory scores (Y-matrix). The cross-validation calibration model is shown in Figure 8. The results show high correlation coefficients for the prediction of 

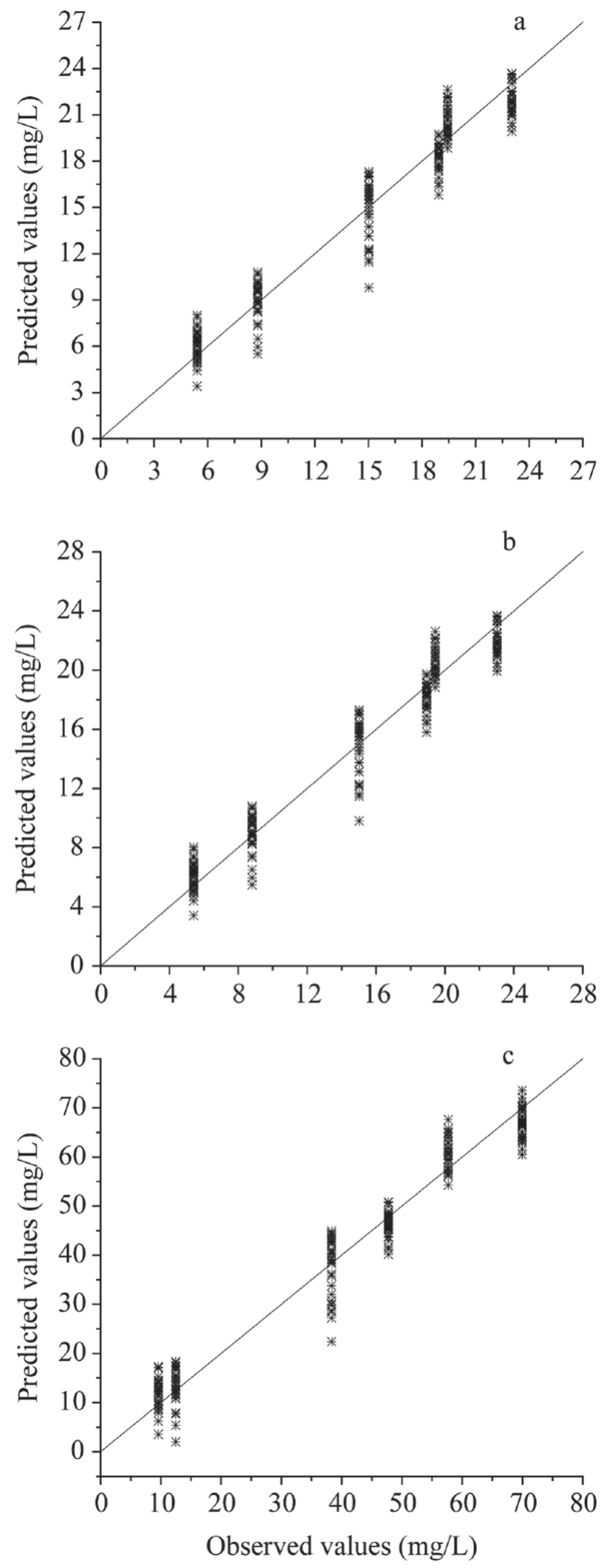

Figure 6. Correlation plots between the actual and predicted values of the content of free fatty acids (a) C6:0; (b) C8:0; (c) C10:0 by partial least squares regression. sensory scores $\left(\mathrm{R}^{2}=0.91\right)$, whereas the accuracy of the prediction was found to be low (RMSECV $=2.22$ ), and the estimated values were not close to the actual values. The model validation was not optimal, indicating the complexity of the relationships between data. One possible reason is that the number of samples was relatively small; however, the most plausible explanation is that the relationship between sensory scores and FFA concentration was nonlinear. Previous studies have suggested that the relationship between sensory intensity and chemical data is consistent with the Weber-Fechner law or the Stevens law (Stone et al., 2012). Furthermore, a lack of some minor branchedchain FFA in the regression equation might also result in poor performance. Further research is necessary to assess fully the relationship between sensory evaluation and FFA concentrations.

\section{Pattern Recognition of the Degree of Goaty Flavor Intensity in Goat Milk Samples from the Electronic Nose Data}

The score plots of PCA and LDA show that the electronic nose had the ability to distinguish among different intensities of goaty flavor in goat milk. To investigate the predictability of the electronic nose regarding intensities of goaty flavor, 2 pattern recognition algorithms - Fisher discriminant analysis (FDA) and BP-NN - were applied. The duplex method (Snee,

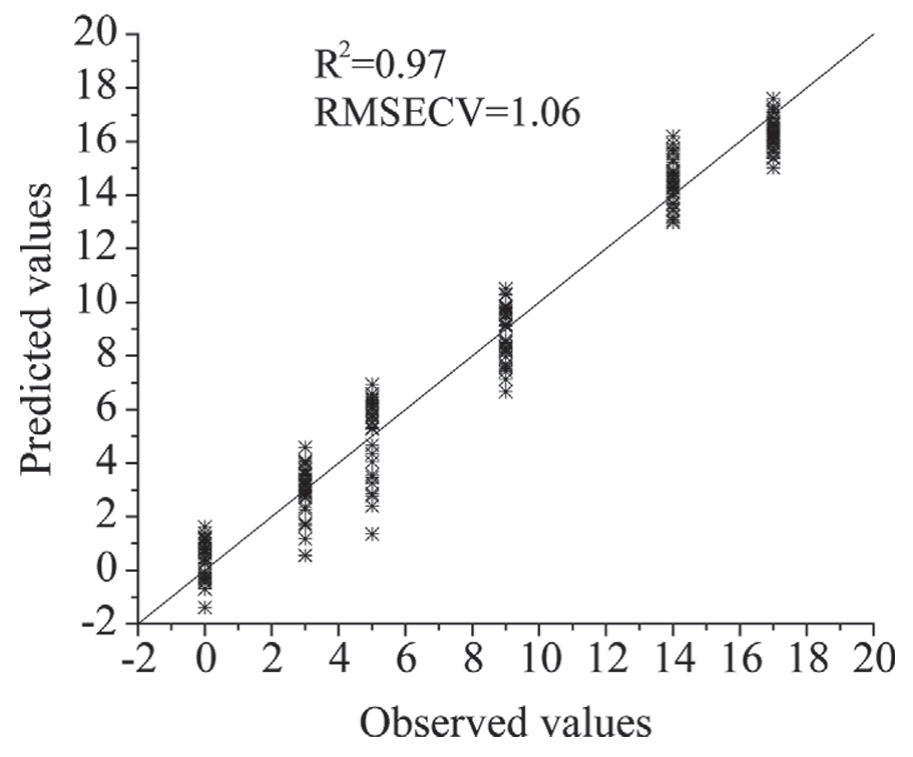

Figure 7. Correlation plots between the actual and predicted scores in sensory evaluation by partial least squares regression with sensor responses as X-matrix. RMSECV $=$ root mean square error of cross-validation. 
Table 4. Results of calibration for GC data on the base of electronic nose signal

\begin{tabular}{lccc}
\hline $\begin{array}{l}\text { Dependent } \\
\text { variable }\end{array}$ & $\mathrm{LV}^{1}$ & $\mathrm{R}^{2}$ & $\begin{array}{c}\mathrm{RMSECV}^{2} \\
(\mathrm{mg} / \mathrm{L})\end{array}$ \\
\hline C6:0 & 7 & 0.96 & 0.57 \\
C8:0 & 7 & 0.94 & 1.48 \\
C10:0 & 7 & 0.96 & 4.48 \\
\hline
\end{tabular}

${ }^{1}$ Number of latent variables in the partial least squares regression.

${ }^{2}$ Root mean square error of cross-validation.

1977) was used to split the 192 measured samples into a training set of 135 samples and a test set of 57 samples.

The training and prediction results of training samples and test samples by FDA are shown in Table 5. Fisher discriminant analysis applied to the sensor responses gave 100\% recognition for all training samples (error rate 0\%), and cross-validation classified all samples correctly (cross-validation error rate $0 \%$ ). For the test samples, a similar high level of correct classification was achievable, and only one sample from the moderate intensity group was misclassified as being from the low intensity group. Figure 9 shows how the first 2 functions of FDA discriminated among classes of the training group samples. Each group was clearly distinguished from the other groups.

In BP-NN, the architecture was three-layer backpropagation. The responsive values collected from 10 sensors were used as input data, and the 4 goaty flavor intensities (none, low, mild, strong) were used as output data. Based on the accuracy of training, the optimum hidden layer unit number was set at 5 , so the network topology was 10-5-4. The optimum learning factor was set at 0.01 and the optimum target error was set at 0.01. As shown in Table 6, all samples in training and test groups were correctly identified. In general, when the investigated data structures are highly complex,

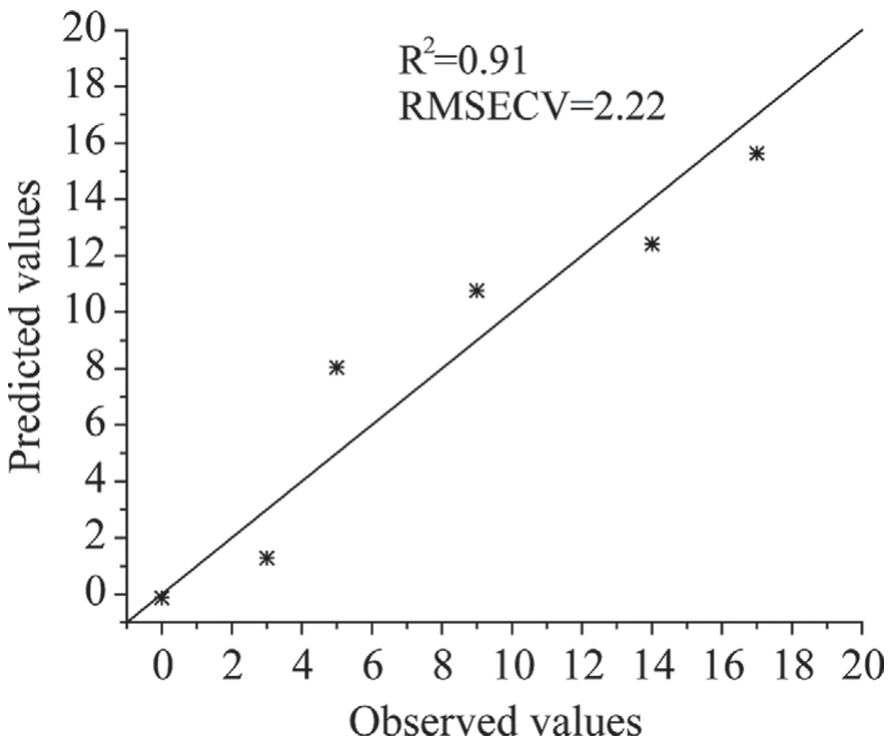

Figure 8. Correlation plots between the actual and predicted scores in sensory evaluation by partial least squares regression with GC data as X-matrix. RMSECV = root mean square error of cross-validation.

neural networks have an advantage over traditional statistical methods (Zhang et al., 2005). In this study, the data structures evaluated were relatively simple and alternative statistical methods (i.e., FDA) yielded similar results. According to the obtained results, we could infer that FDA and BP-NN applied to electronic nose data was particularly useful to classify the 4 groups of samples.

\section{CONCLUSIONS}

In this study, an electronic nose based on metal oxide sensors was used to measure goaty flavor of goat milk samples. The goat milk samples with different

Table 5. Classification of samples by Fisher discriminant analysis

\begin{tabular}{|c|c|c|c|c|c|c|c|}
\hline \multirow[b]{2}{*}{ Group } & \multirow{2}{*}{$\begin{array}{l}\text { Actual } \\
\text { group }^{1}\end{array}$} & \multirow{2}{*}{$\begin{array}{l}\text { Group } \\
\text { size }\end{array}$} & \multicolumn{4}{|c|}{ Predicted group ${ }^{1}$} & \multirow{2}{*}{$\begin{array}{c}\text { Accuracy } \\
(\%)\end{array}$} \\
\hline & & & None & Low & Mild & Strong & \\
\hline \multirow[t]{4}{*}{ Training group } & None & 28 & 28 & \multirow{4}{*}{48} & \multirow{4}{*}{17} & & 100.0 \\
\hline & Low & 48 & & & & & 100.0 \\
\hline & Mild & 17 & & & & & 100.0 \\
\hline & Strong & 42 & & & & 42 & 100.0 \\
\hline \multirow[t]{5}{*}{ Cross validation } & & & & & & & \\
\hline & None & 28 & 28 & \multirow{4}{*}{48} & & & 100.0 \\
\hline & Low & 48 & & & & & 100.0 \\
\hline & Mild & 17 & & & 17 & & 100.0 \\
\hline & Strong & 42 & & & & 42 & 100.0 \\
\hline \multirow[t]{4}{*}{ Test group } & & & 4 & & & & 1000 \\
\hline & Low & $\begin{array}{r}4 \\
16\end{array}$ & 4 & \multirow{3}{*}{$\begin{array}{r}16 \\
1\end{array}$} & \multirow{3}{*}{14} & & $\begin{array}{l}100.0 \\
100.0\end{array}$ \\
\hline & Mild & 15 & & & & & 93.3 \\
\hline & Strong & 22 & & & & 22 & 100.0 \\
\hline
\end{tabular}

${ }^{1}$ Goaty flavor intensities: none $=$ sample score is 0 ; low $=$ sample score is $\geq 1$ and $<4$; mild $=$ sample score is $\geq 4$ and $<7$; strong $=$ sample score is $\geq 7$. 


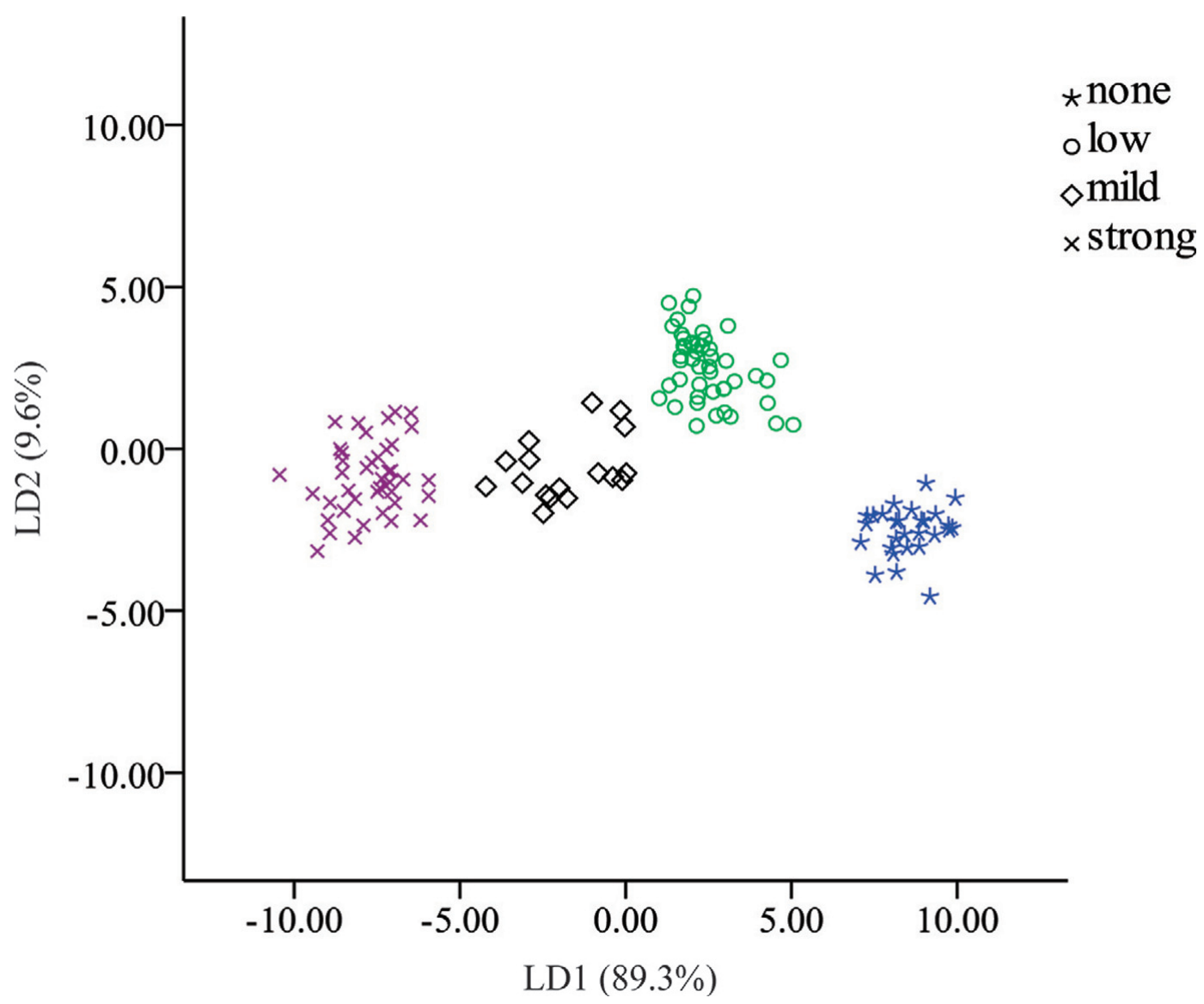

Figure 9. Linear discriminant (LD) analysis plot of training group samples of goat milk with LD1 and LD2. Goaty flavor intensities: none $=$ sample score is 0 ; low $=$ sample score is $\geq 1$ and $<4$; mild $=$ sample score is $\geq 4$ and $<7$; strong $=$ sample score is $\geq 7$. Color version available online.

goaty flavor intensities were discerned by PCA and LDA, whereas FDA and BP-NN were carried out to identify the goaty flavor intensities. The prediction accuracies obtained from FDA and BP-NN were 98.2 and $100.0 \%$, respectively. The results from the present study also revealed a positive correlation between electronic nose sensor system and sensory attributes. Use of the electronic nose, in combination with appropriate multivariate statistical analysis, is a promising tool for discerning and characterizing the different intensities of goaty flavor in goat milk. Despite promising results by the electronic nose, this is a preliminary feasibility study because the number of samples was small. Caution must be exercised in extending the applicability

Table 6. Classification of samples by back-propagation neural network

\begin{tabular}{|c|c|c|c|c|c|c|c|}
\hline \multirow[b]{2}{*}{ Group } & \multirow[b]{2}{*}{$\begin{array}{l}\text { Actual } \\
\text { group }^{1}\end{array}$} & \multirow[b]{2}{*}{$\begin{array}{l}\text { Group } \\
\text { size }\end{array}$} & \multicolumn{4}{|c|}{ Predicted group ${ }^{1}$} & \multirow{2}{*}{$\begin{array}{c}\text { Accuracy } \\
(\%)\end{array}$} \\
\hline & & & None & Low & Mild & Strong & \\
\hline \multirow[t]{4}{*}{ Training group } & None & 28 & 28 & \multirow{4}{*}{48} & & & 100.0 \\
\hline & Low & 48 & & & & & 100.0 \\
\hline & Mild & 17 & & & 17 & & 100.0 \\
\hline & Strong & 42 & & & & 42 & 100.0 \\
\hline \multirow[t]{4}{*}{ Test group } & None & 4 & 4 & \multirow{4}{*}{16} & & & 100.0 \\
\hline & Low & 16 & & & & & 100.0 \\
\hline & Mild & 15 & & & 15 & & 100.0 \\
\hline & Strong & 22 & & & & 22 & 100.0 \\
\hline
\end{tabular}

${ }^{1}$ Goaty flavor intensities: none $=$ sample score is 0 ; low $=$ sample score is $\geq 1$ and $<4$; mild $=$ sample score is $\geq 4$ and $<7$; strong $=$ sample score is $\geq 7$. 
and reliability of the technique to discriminate between more samples until further validation is completed. Furthermore, increased research efforts to improve gas sensor properties and explore the response mechanism of the sensor are important and necessary. These refinements will make the electronic nose technique a practical tool for discriminating and characterizing goaty flavor at the industry and research levels.

\section{ACKNOWLEDGMENTS}

This work was supported by the Special Fund for Agro-Scientific Research in the Public Interest (China; $3-45)$.

\section{REFERENCES}

Airsense Analytics GmbH. 2008. Portable Electronic Nose PEN 3 handbook. 3rd rev. ed. Airsense Analytics GmbH, Schwerin, Germany.

Ali, Z., W. O'Hare, and B. Theaker. 2003. Detection of bacterial contaminated milk by means of a quartz crystal microbalance based electronic nose. J. Therm. Anal. Calorim. 71:155-161.

Annor-Frempong, I. E., G. R. Nute, J. D. Wood, F. W. Whittington, and A. West. 1998. The measurement of the responses to different odour intensities of 'boar taint' using a sensory panel and an electronic nose. Meat Sci. 50:139-151.

Arroyo, T., J. Lozano, J. M. Cabellos, M. Gil-Diaz, J. P. Santos, and C. Horrillo. 2009. Evaluation of wine aromatic compounds by a sensory human panel and an electronic nose. J. Agric. Food Chem. 57:11543-11549.

Brennand, C., J. Kin Ha, and R. Lindsay. 1989. Aroma properties and thresholds of some branched-chain and other minor volatile fatty acids occurring in milkfat and meat lipids. J. Sens. Stud. 4:105-120.

Brennand, C., and R. Lindsay. 1982. Sensory discrimination of speciesrelated meat flavors. Lebenson. Wiss. Technol. 5:249-252.

Capone, S., M. Epifani, F. Quaranta, P. Siciliano, A. Taurino, and L. Vasanelli. 2001. Monitoring of rancidity of milk by means of an electronic nose and a dynamic PCA analysis. Sens. Actuators B Chem. 78:174-179.

Capone, S., M. Epifani, R. Rella, P. Siciliano, and L. Vasanelli. 2000a. Response of $\mathrm{SnO}_{2}$ thin film sensors to the odors of parmesan cheese. Sens. Mater. 12:109-115.

Capone, S., P. Siciliano, F. Quaranta, R. Rella, M. Epifani, and L. Vasanelli. 2000b. Analysis of vapours and foods by means of an electronic nose based on a sol-gel metal oxide sensors array. Sens. Actuators B Chem. 69:230-235.

Chilliard, Y., A. Ferlay, J. Rouel, and G. Lamberet. 2003. A review of nutritional and physiological factors affecting goat milk lipid synthesis and lipolysis. J. Dairy Sci. 86:1751-1770.

Collins, Y. F., P. L. McSweeney, and M. G. Wilkinson. 2003. Lipolysis and free fatty acid catabolism in cheese: A review of current knowledge. Int. Dairy J. 13:841-866.

Cozzolino, D., H. E. Smyth, W. Cynkar, R. G. Dambergs, and M. Gishen. 2005. Usefulness of chemometrics and mass spectrometrybased electronic nose to classify Australian white wines by their varietal origin. Talanta 68:382-387.

Di Natale, C., G. Pennazza, A. Macagnano, E. Martinelli, R. Paolesse, and A. D'Amico. 2003. Thickness shear mode resonator sensors for the detection of androstenone in pork fat. Sens. Actuators B Chem. 91:169-174.

Echeverría, G., E. Correa, M. Ruiz-Altisent, J. Graell, J. Puy, and L. López. 2004. Characterization of Fuji apples from different harvest dates and storage conditions from measurements of volatiles by gas chromatography and electronic nose. J. Agric. Food Chem. 52:3069-3076

Eknæs, M., K. Kolstad, H. Volden, and K. Hove. 2006. Changes in body reserves and milk quality throughout lactation in dairy goats. Small Rumin. Res. 63:1-11.

Eriksson, Å., K. Persson Waller, K. Svennersten-Sjaunja, J. Haugen, F. Lundby, and O. Lind. 2005. Detection of mastitic milk using a gas-sensor array system (electronic nose). Int. Dairy J. 15:11931201.

Fernandes, D. L., and M. Gomes. 2008. Development of an electronic nose to identify and quantify volatile hazardous compounds. Talanta $77: 77-83$.

Gardner, J. W., and P. N. Bartlett. 1994. A brief history of electronic noses. Sens. Actuators B Chem. 18:210-211.

Grazier, C., F. Bodyfelt, M. McDaniel, and J. Torres. 1991. Temperature effects on the development of Cheddar cheese flavor and aroma. J. Dairy Sci. 74:3656-3668.

Grigioni, G. M., C. A. Margaria, N. A. Pensel, G. Sanchez, and S. R. Vaudagna. 2000. Warmed-over flavour analysis in low temperature-long time processed meat by an "electronic nose". Meat Sci. $56: 221-228$

Haenlein, G. 2004. Goat milk in human nutrition. Small Rumin. Res. $51: 155-163$.

Haugen, J.-E., and K. Kvaal. 1998. Electronic nose and artificial neural network. Meat Sci. 49 (Suppl. 1):S273-S286.

He, W., X. Hu, L. Zhao, X. Liao, Y. Zhang, M. Zhang, and J. Wu. 2009. Evaluation of Chinese tea by the electronic tongue: Correlation with sensory properties and classification according to geographical origin and grade level. Food Res. Int. 42:1462-1467.

He, Y., S. Feng, X. Deng, and X. Li. 2006. Study on lossless discrimination of varieties of yogurt using the visible/NIR-spectroscopy. Food Res. Int. 39:645-650.

ISO. 2003. ISO 4121: Sensory analysis - Guidelines for the use of quantitative response scales. International Organization for Standardization (ISO), Geneva, Switzerland.

ISO. 2012. ISO 8586: Sensory analysis - General guidelines for the selection, training and monitoring of selected assessors and expert sensory assessors. International Organization for Standardization (ISO), Geneva, Switzerland.

Jirillo, F., and T. Magrone. 2014. Anti-inflammatory and anti-allergic properties of donkey's and goat's milk. Endocr. Metab. Immune Disord. Drug Targets 14:27-37.

Jou, K. D., and W. J. Harper. 1998. Pattern recognition of Swiss cheese aroma compounds by SPME/GC and an electronic nose. Milchwissenschaft 53:259-263.

Kim Ha, J., and R. C. Lindsay. 1993. Release of volatile branchedchain and other fatty acids from ruminant milk fats by various lipases. J. Dairy Sci. 76:677-690.

Labreche, S., S. Bazzo, S. Cade, and E. Chanie. 2005. Shelf life determination by electronic nose: application to milk. Sens. Actuators B Chem. 106:199-206.

Magan, N., A. Pavlou, and I. Chrysanthakis. 2001. Milk-sense: A volatile sensing system recognises spoilage bacteria and yeasts in milk. Sens. Actuators B Chem. 72:28-34.

Miettinen, S. M., V. Piironen, H. Tuorila, and L. Hyvönen. 2002. Electronic and human nose in the detection of aroma differences between strawberry ice cream of varying fat content. J. Food Sci $67: 425-430$

Morgan, F., and P. Gaborit. 2001. The typical flavour of goat milk products: technological aspects. Int. J. Dairy Technol. 54:38-40.

Nake, A., B. Dubreuil, C. Raynaud, and T. Talou. 2005. Outdoor in situ monitoring of volatile emissions from wastewater treatment plants with two portable technologies of electronic noses. Sens. Actuators B Chem. 106:36-39.

Ohmori, S., Y. Ohno, T. Makino, and T. Kashihara. 2005. Application of an electronic nose system for evaluation of unpleasant odor in coated tablets. Eur. J. Pharm. Biopharm. 59:289-297.

Patton, S. 1964. Flavor thresholds of volatile fatty acids. J. Food Sci. 29:679-680. 
Persaud, K. C., S. M. Khaffaf, P. J. Hobbs, and R. W. Sneath. 1996. Assessment of conducting polymer odour sensors for agricultural malodour measurements. Chem. Senses 21:495-505.

Pillonel, L., S. Ampuero, R. Tabacchi, and J. Bosset. 2003. Analytical methods for the determination of the geographic origin of Emmental cheese volatile compounds by GC/MS-FID and electronic nose. Eur. Food Res. Technol. 216:179-183.

Qin, Z., X. Pang, D. Chen, H. Cheng, X. Hu, and J. Wu. 2013. Evaluation of Chinese tea by the electronic nose and gas chromatography-mass spectrometry: Correlation with sensory properties and classification according to grade level. Food Res. Int. 53:864-874.

Raynal-Ljutovac, K., G. Lagriffoul, P. Paccard, I. Guillet, and Y. Chilliard. 2008. Composition of goat and sheep milk products: An update. Small Rumin. Res. 79:57-72.

Rodriguez-Campos, J., H. B. Escalona-Buendia, I. Orozco-Avila, E. Lugo-Cervantes, and M. E. Jaramillo-Flores. 2011. Dynamics of volatile and non-volatile compounds in cocoa (Theobroma cacao L.) during fermentation and drying processes using principal components analysis. Food Res. Int. 44:250-258.

Russo, M., R. di Sanzo, V. Cefaly, S. Carabetta, D. Serra, and S. Fuda. 2013. Non-destructive flavour evaluation of red onion ( $\mathrm{Al}$ lium cepa L.) ecotypes: An electronic-nose-based approach. Food Chem. 141:896-899.

Salles, C., N. Sommerer, C. Septier, S. Issanchou, C. Chabanet, A. Garem, and J. L. L. Quéré. 2002. Goat cheese flavor: Sensory evaluation of branched-chain fatty acids and small peptides. J. Food Sci. 67:835-841.

Santos, J. P., J. Lozano, M. Aleixandre, T. Arroyo, J. M. Cabellos, M. Gil, and M. C. Horrillo. 2010. Threshold detection of aromatic compounds in wine with an electronic nose and a human sensory panel. Talanta 80:1899-1906.

Siek, T., I. A. Albin, L. A. Sather, and R. Lindsay. 1969. Taste thresholds of butter volatiles in deodorized butteroil medium. J. Food Sci. 34:265-267.

Skjevdal, T. 1979. Flavour of goat's milk: A review of studies on the sources of its variations. Livest. Prod. Sci. 6:397-405.

Smyth, H., and D. Cozzolino. 2013. Instrumental methods (spectroscopy, electronic nose, and tongue) as tools to predict taste and aroma in beverages: Advantages and limitations. Chem. Rev 113:1429-1440.

Snee, R. D. 1977. Validation of regression models: Methods and examples. Technometrics 19:415-428.

Sohn, J. H., R. Smith, E. Yoong, J. Leis, and G. Galvin. 2003. Quantification of odours from piggery effluent ponds using an electronic nose and an artificial neural network. Biosystems Eng. 86:399410.
Song, S. Q., L. Yuan, X. M. Zhang, K. Hayat, H. N. Chen, F. Liu, Z. B. Xiao, and Y. W. Niu. 2013. Rapid measuring and modelling flavour quality changes of oxidised chicken fat by electronic nose profiles through the partial least squares regression analysis. Food Chem. 141:4278-4288

Spaepen, M., D. Oevelen, and H. Verachtert. 1978. Fatty acids and esters produced during the spontaneous fermentation of lambic and gueuze. J. Inst. Brew. 84:278-282.

Stone, H., R. Bleibaum, and H. A. Thomas. 2012. Sensory Evaluation Practices. 3rd ed. Elsevier Press, Singapore.

Strzałkowska, N., E. Bagnicka, E. Poławska, J. Krzyżewski, and B. Pyzel. 2012. Fatty acid profiles, cholesterol concentration, and susceptibility to lipolytic fat fraction in goat's milk. Med. Weter. 68:40-44

Stuetz, R., R. Fenner, and G. Engin. 1999. Assessment of odours from sewage treatment works by an electronic nose, $\mathrm{H}_{2} \mathrm{~S}$ analysis and olfactometry. Water Res. 33:453-461.

Tamaki, K., S. Sonoki, T. Tamaki, and K. Ehara. 2008. Measurement of odour after in vitro or in vivo ingestion of raw or heated garlic, using electronic nose, gas chromatography and sensory analysis. Int. J. Food Sci. Technol. 43:130-139.

Tian, X., J. Wang, and S. Cui. 2013. Analysis of pork adulteration in minced mutton using electronic nose of metal oxide sensors. J Food Eng. 119:744-749.

Tikk, K., J.-E. Haugen, H. J. Andersen, and M. D. Aaslyng. 2008. Monitoring of warmed-over flavour in pork using the electronic nose-correlation to sensory attributes and secondary lipid oxidation products. Meat Sci. 80:1254-1263.

Verboven, S., and M. Hubert. 2005. LIBRA: A MATLAB library for robust analysis. Chemom. Intell. Lab. Syst. 75:127-136.

Vestergaard, J. S., J. E. Haugen, and D. V. Byrne. 2006. Application of an electronic nose for measurements of boar taint in entire male pigs. Meat Sci. 74:564-577.

Wilson, A. D., and M. Baietto. 2009. Applications and advances in electronic-nose technologies. Sensors (Basel) 9:5099-5148.

Woo, A., and R. Lindsay. 1983. Statistical correlation of quantitative flavor intensity assessments and individual free fatty acid measurements for routine detection and prediction of hydrolytic rancidity off-flavors in butter. J. Food Sci. 48:1761-1766.

Zhang, H., M. Balaban, J. C. Principe, and K. Portier. 2005. Quantification of spice mixture compositions by electronic nose: part I. Experimental design and data analysis using neural networks. J. Food Sci. 70:E253-E258.

Zhang, H., J. Wang, X. Tian, H. Yu, and Y. Yu. 2007. Optimization of sensor array and detection of stored duration of wheat by electronic nose. J. Food Eng. 82:403-408. 